\title{
Anthropogenic landslide geodetic monitoring
}

\author{
Vladislav Zaalishvili*, and Dmitry Melkov \\ Geophysical Institute - the Affiliate of Vladikavkaz Scientific Center of the Russian Academy of Sciences, 362002, \\ Vladikavkaz, Russia
}

\begin{abstract}
The first results of monitoring the slow dynamics of an anthropogenic landslide located in the mountainous part of the Republic of North Ossetia-Alania are presented in the article. Landslide motion measurements were performed using tacheometric surveying and the GPS/GLONASS global positioning system. The article considers the selection of sites for installation the basic network points for landslides monitoring.
\end{abstract}

\section{Introduction}

The most widespread landslide processes are observed in the mountainous part of North Ossetia, especially in the zone of the Northern Jurassic intermountain depression, the sub escarp zone of the Scalisty Range, in the areas of the Southern intermountain depression and the Glavny Vodorazdelny Range. According to the scale, hazard and nature of their manifestation, they are divided into landslides, mudslides and sluffs. Landslides are large, have a significant depth of incorporation (up to tens of meters) and a volume of more than $100 \mathrm{~m}^{3}$. The reason for their formation is a steep slope, seismic shocks, bedding conditions of the slope rocks. Mudslides and sluffs are smaller (up to 100 cubic meters) and can be caused by human activity, i.e., slopes cutting during road building, mining, etc. Among 350 landslides explored in the mountains of North Ossetia, the following are distinguished by size: small (up to 1 thousand cubic meters), medium (up to 100 thousand cubic meters), large (up to 1 million cubic meters) and very large (with a volume of more than 1 million cubic meters). Examples of very large landslides are the Luar, Donifars, N. Nar and other landslides. The processes of large-scale landslides development cover an area of 2300 sq. km. The causes of landslides have both natural and anthropogenic nature [1-8].

The main factor of landslide processes activation is the excessive watering of slopes, which occurs during snowmelt and heavy rains. A sharp increase in river runoff contributes significantly to the landslides activity; as a result, the erosion and destruction of the landslides frontal parts occur, which often leads to the displacements of the overlying masses, as was observed on the Luar landslide in 1984 and on the Matsuta landslide in 1991. However, the quantitative relationship of atmospheric precipitation and other meteorological factors influence have not been previously studied in the explored area. Geodetic measurements were carried out only once a year on the large landslides, which represent the greatest hazard, and the influence of meteorological factors can be judged by the average annual data.

A noticeable increase in landslide activity is caused by seismic impacts associated with modern tectonic movements. In particular, the movements of the Matsuta and Donifars landslides in 1990 and the Ursdon landslide in 1993 are associated with tectonic movements. A retrospective analysis of the formation and large activation of landslides in the 20th century indicates that some of them are directly related to earthquakes (Dallagkau landslide, 1905; Korinskiy landslide, 1915 and Turmonskiy, 1981, etc.). However, such conclusion is based only on those cases when the fall (or movement) of the landslide coincided directly with a strong shock (more than 4-5 intensity points).

Recently, an increasingly significant role in the landslides activation has been played by anthropogenic factor, in particular, the cutting of slopes during the construction. A demonstrative example of such cases is the

\footnotetext{
* Corresponding author: cgi_ras@mail.ru
} 
Fiagdon landslide in the Republic of North Ossetia-Alania (Fig. 1). The landslide was formed as a result of the slope cutting during the liquidation of Fiagdon tailing dump of the Fiagdon concentrating mill (summer-autumn 2019).

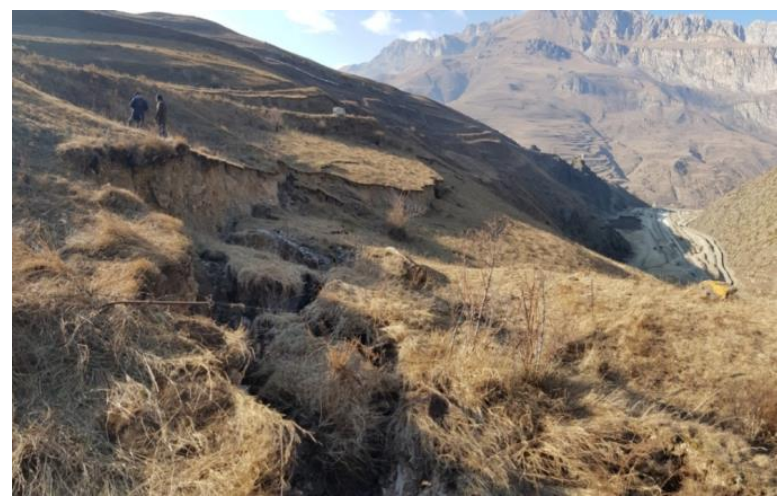

Fig. 1. Wall of landslideseparation caused by cutting of the lower part of the slope during the liquidation of Fiagdon tailing dump, photo: December 2019

\section{Geodetic methods}

Measurement of the geometrical characteristics of the earth's surface is a critical phase of any large project of civil engineering construction. Structural deformation and ground displacement during landslides can be monitored using various types of systems and methods. These methods and tools can be classified as remote sensing or satellite, photogrammetric and geodetic methods. The choice of tools and measurement methods or the creation of a special monitoring system depends on the different types of deformation that will influence the method of stability analysis and therefore the entire deformation monitoring system [9-21].

Satellite images in the optical region with a high spatial resolution are used to compile landslide inventory maps. Satellite data is used to supplement aerial photography or as a substitution in case of no aerial imagery available recently. Also, satellite imagery is a more cost-effective database for regional and national hazard zoning. Another advantage of satellite remote sensing is the ability of the repeated observation, which results in more frequent information updates of landslide characteristics than in traditional data sources. Using the small satellite imagery scales, only very large landslides can be identified directly. The value of satellite imagery consists in the fact that the area susceptibility to landslides can be determined indirectly by some signs that can be identified within these scales. Satellite imagery reveals regional physiography, geology and most landforms, as well as land use practices and vegetation distribution. This method is suitable for preliminary analysis of large areas (for example, the Luar landslide).

Another important application of the Earth observation data is the creation of digital elevation models (DEM), which provide basic information for slope characterization and numerical modeling. Models for the large areas can be obtained with the help of the satellite data such as GTOPO30 with a resolution of $1 \mathrm{~km}$. For the local areas, the scanning with a resolution of up to fractions of a meter can be performed; it all depends on the speed of the equipment and the expediency of the problem being solved.

The use of robotic tacheometers gives the possibility of collecting 3D position information for automatic deformation monitoring. They can measure the angles and distances automatically. Due to modern technology tacheometers are capable of measuring angles with an accuracy of 1 second and distances with an accuracy of \pm $1 \mathrm{~mm}$. at the distances up to $3500 \mathrm{~m}$ (accuracy is decreasedwith distance). Tacheometers allow measuring many points with prismatic targets on a controlled surface in a short period. Using Automatic Target Recognition (ATR) technology, each prism can be found and centered to ensure accurate targeting. These technologies are ideal for precision applications where the elimination of error sources is desired. However, using a sufficient number of prisms for permanent installation on a slope is economically impractical; prisms are also precision optical devices that can be easily damaged not only by vandalism but also by natural factors. In case of prism movement and manual installation, the advantage of using a tacheometer that can take measurements at a distance get lost. We investigated various reflective surfaces to provide stable measurement over the long distances for the Luar landslide. The use of a robotic tacheometer allows aiming at the reflectors automatically, 
based on the results of the previous measurements. The created system requires the participation of the operator to aim accurately at the cross of the reflector, however, it still significantly reduces the work on regular geodetic monitoring. The disadvantage of using a tacheometric survey is the need for a line of sight to take measurements. However, in all cases for all objects, we managed to select survey points that cover the most important areas for monitoring. In case of necessity, GPS technology can be used.

Ground survey with a Trimble S7 robotic tacheometer. The example of scanning the slope section of a small landslide (Fiagdon tailing dump) is shown in Fig. 2. The photogrammetric method was also used; surveying was carried out by a DJI Phantom 4 Pro quadcopter.

\section{Slope stability assessment}

To select sites for installation the points of the basic horizontal network for landslides monitoring, an assessment of the stability of the slopes in the area of the landslide was carried out.

Scoops3D is a computer program developed by the United States Geological Survey (USGS) for analyzing slope stability across the entire digital landscape, represented by a digital elevation model (DEM). It detects large numbers and calculates the stability of 3D potential landslides covering a wide range of depths and volumes. Scoops3D uses a three-dimensional "column method" of limited equilibrium analysis to calculate the resilience of potential slope failures (landslides) with a spherical potential slip area. Scoops3D has a wide range of user options: it can include complex topography, full 3D distribution of parameters including subsurface material properties and pore water pressure, and simplified seismic actions in the form of maximum horizontal accelerations. The approach was originally described in [22]. The results of Scoops3D analysis show the minimum safety factor (stability index) for potential slip areas affecting each DEM cell throughout the landscape, as well as for volumes or areas associated with these potential damages of slopes.

Scoops3D has been designed to solve several problems. To calculate the relative stability of slopes across the entire landscape, and thereby perform regional assessments of landslide susceptibility, as a screening tool for identifying areas of low stability in the landscape, which may require further detailed stability analysis. Besides, Scoops3D can be used to assess differences in stability resulting from a series of possible scenarios, such as the effects of different groundwater flow regimes or spatial variations in soil material properties. The Scoops3D program has been used to assess the stability of volcanic edifices on Mount Rainer in Washington [22], the Casita Volcano in Nicaragua [23], Augustine volcano in Alaska [24] and the mountain St. Helens before the collapse $[23 ; 25]$. The program was also supplemented with a 3D regional groundwater flow model and was used to analyze the stability of coastal cliffs in Seattle, Washington [26; 27].

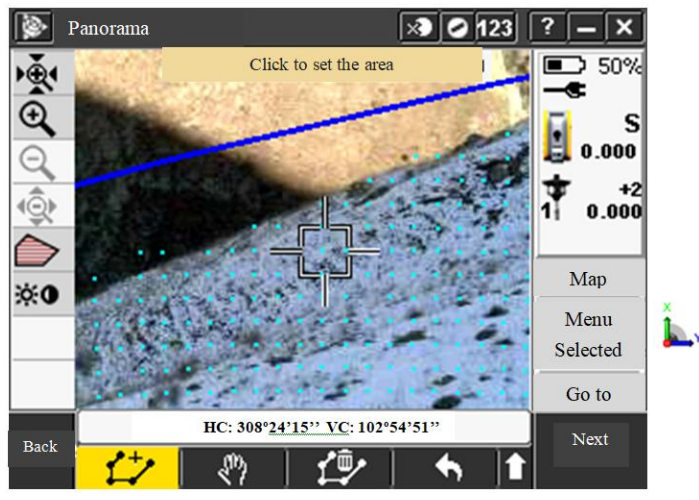

a)

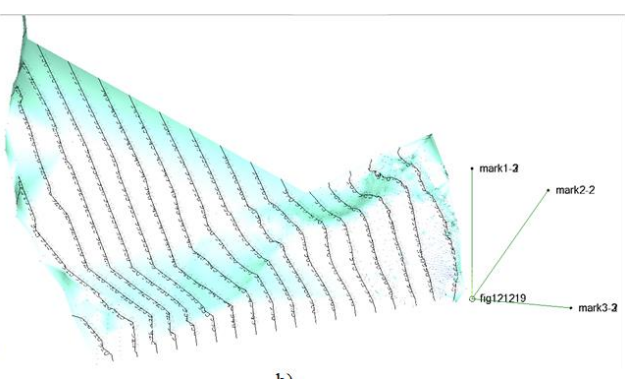

(b)

Fig. 2. Fragment of the Fiagdon landslide in the process of scanning (a) and a digital surface model calculated using point cloud (b)

Scoops3D allows the user to choose between two well-known geotechnical methods of the moment equilibrium for calculating the rotating surfacestability: the conventional Fellenius method and the simplified Bishop method [28]. Both methods are computationally efficient and work well with 3D columns defined with a digital elevation model. Both methods calculate stability using moment equilibrium about an axis of rotation. 
None of them requires calculating lateral forces between columns, and thus they avoid the difficulty of calculating lateral forces on column sides that are not aligned with the DEM mesh [29].

We used the Bishop method in our calculations. The simplified Bishop method provides safety factor values similar to those obtained with more rigorous stability methods (such as the Spencertechnique or MorgensternPrice method) in 2D [30;31] as well as in 3D [33-34]. The simplified Bishop method requires an iterative solution method to compute $F$; and the iteration process sometimes couldn't converge to a solution or converges to a false (i.e., incorrect) solution, especially if the test surface includes very steep slip areas or is subjected to the high pour water pressure. Scoops 3D allows the user to filter out false decisions.

When performing a slope stability analysis, Scoops $3 \mathrm{D}$ calculates the shear strength s on the test surface using the Coulomb-Terzaghi linear fracture rule [35]:

$$
s=c+\left(\sigma_{n}-u\right) \operatorname{tg} \varphi
$$

where $c$ is the adhesion, $\varphi$ is the angle of internal friction, $\sigma_{n}$ is the normal stress, $u$ is the pore water pressure influencing the shear surface. This rule can be used for many standard geotechnical analyses, including total stress (where $u=0)$ and effective stress $(u \neq 0)$ analyses, as well as undrained $(\varphi=0)$ analysis.

Scoops 3D calculates the safety factor $\mathrm{F}$ for a given test surface using moment equilibrium [35]. In general, all limited equilibrium methods (including moment equilibrium methods) define $F$ as the ratio of the average shear strength $\mathrm{s}$ to the shear stress $\tau$ required for maintaining limit equilibrium along a predetermined test surface [35]:

$$
\mathrm{F}=\mathrm{s} / \tau
$$

$F$ values less than one indicate instability. A fixed $l / F$ ratio of the available shear strength is opposed to the shear stress at equilibrium (fundamental assumption of the method), or:

$$
\tau=\mathrm{s} / \mathrm{F}
$$

For the finite areas, such as a common test surface or the base of a single column, we need to use the forces or stresses influencing the area. Thus, the average force of shear strength at the equilibrium state $T$ is equal to:

$$
T=\frac{1}{A} \int_{A} \frac{s A}{F} d A
$$

where $A$ is the total test surface area.

Discretization of the shear strength over an ensemble of vertical columns in the potential destruction mass determined by the altitude matrix and indexed by $i$ and $j$ in the $x$ and $y$ directions, correspondingly, leads to:

$$
T=\frac{1}{F} \sum S_{i, j} A_{i, j}
$$

where $A_{i, j}$ is the test surface area at the base of each column $i, j$. The value of $A_{i, j}$ varies depending on the slope of the base and on the fact whether the column covers a full or partial DEM cell. $F$ is assumed to be the same for each column.

As a result, the assessment of the value of the safety factor $F$ is obtained (Fig. 3) for each element of the terrain model (excluding boundary elements). As consequence, the points of the basic network (mark 1, mark 2, mark 3 ) were placed in the areas corresponding to the maximum potential stability of the slope.

\section{Geodetic monitoring}

To measure the dynamics of the landslide body, a local geodetic network was created (Fig. 4). Reference points (Fig. 5) were installed on the stationary part of the slope, above the landslide body and cleavage cracks. In this case, the following criteria were considered according to their importance: reference points should (1) be in the line of sight from the survey point; (2) have the greatest possible different angles from the surveying point; (3) be accessible for installing a deviation prism. The assumption about the immobility of reference points is conditional and periodically monitored by GPS/GLONASS. 


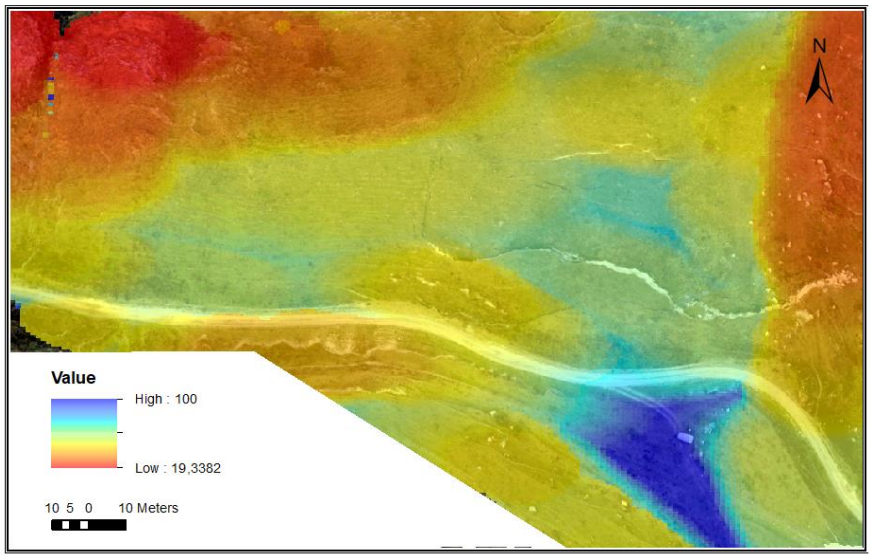

Fig. 3. The results of the safety factor $F$ calculation for the area under study

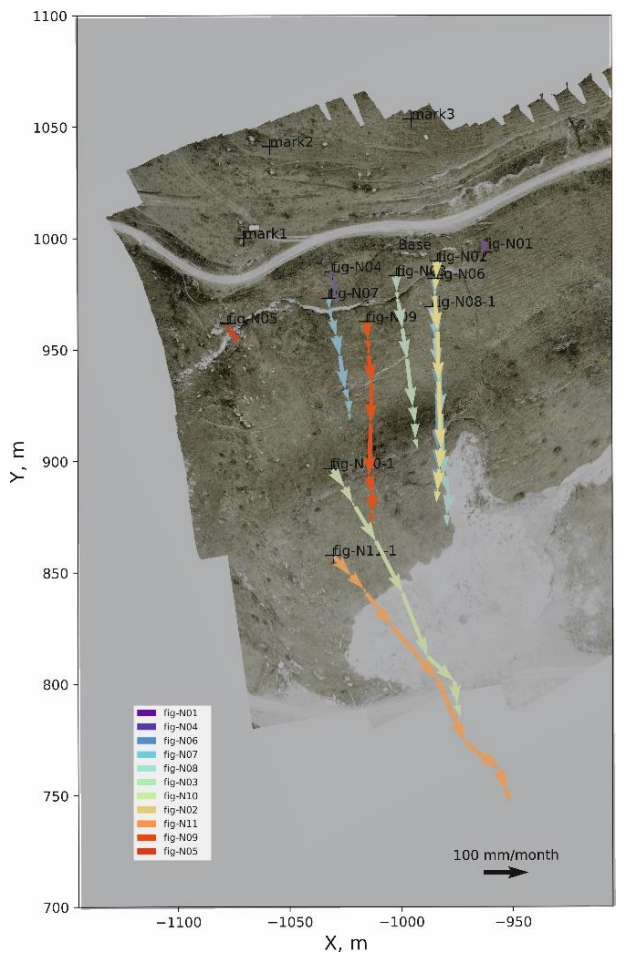

Fig. 4. Dynamics of the displacement velocities for reference points during the observation period plotted on the orthoplan 

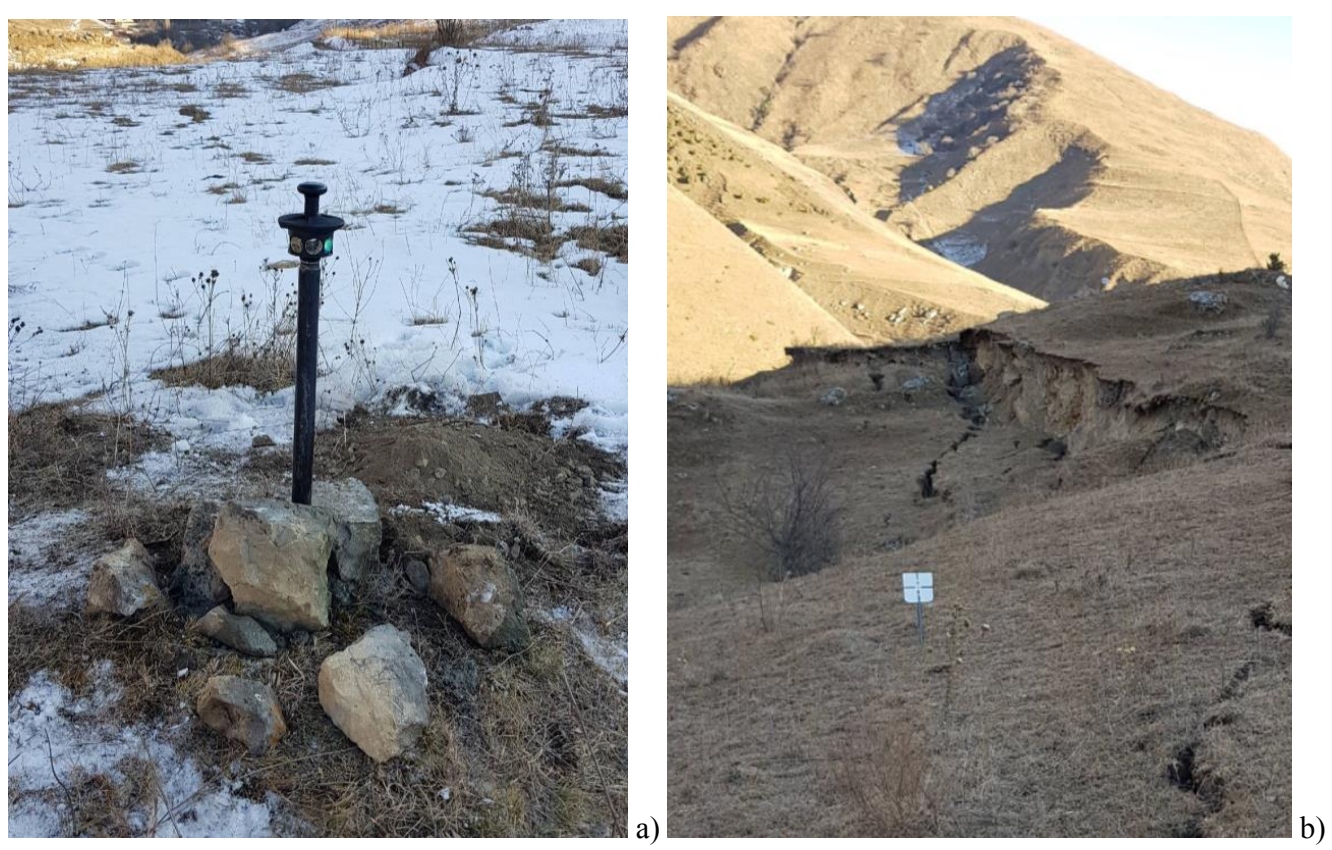

Fig. 6. Arrangement of the reference point with a prism installed at the time of measurements (a) and a reference point reflector (b)

During the considered period, the displacements of the reference points were within the accuracy of the method. The measurements were carried out with a robotic tacheometer Trimble S7. The tacheometer was installed according to the reference points using a reflective prism; points on the landslide body were surveyed remotely, for this, permanent reflectors, oriented in the direction of the permanent survey (the area indicated on the scheme as "Base") were used. The tacheometer was aimed manually; the measurements were carried out in reflectorless mode.

\section{Summary}

To study the movement of soil masses on the left side of the Khanikomdon River, which occurred as a result of the slope cutting during the liquidation of the tailing dump of the Fiagdon concentrating mill (in autumn of 2019), a surface survey was carried out with the help of the surface laser scanning method and photogrammetry using a quadrocopter. Based on the created digital elevation model using the Scoops program, an assessment of the relative stability of slopes in the landslide area was carried out, according to the results of which the sites were selected for installing the reference points (mark-1, mark-2, mark-3).

The following data on point displacements were obtained as a result of the measurements performed over several months (Fig. 4). Eight monitoring points moved during each period of the survey, three points located above the wall of separation (fig-N01, Fig-N04 and fig-N05) did not experience significant movements. The horizontal displacements were approximately twice larger than the vertical ones. The highest velocities were observed on the lower landslide terraces - points fig-N10 and fig-N11. The difference in direction for this part is caused by the landform and less pressure from the left side.

In general, all the displacements have a pronounced seasonal nature [36-38] and differ only in the absolute values of the displacements. Distinct peaks of velocity occur in spring and summer, while minimum velocities are observed in autumn and winter. The velocity values noticeably increase in going from the upper part of the landslide slope to its lower part.

The research was supported by the Russian Science Foundation (Project No. 19-47-02010 RSF -DST (2018): "Natural hazards and monitoring for mountain territories in Russia and India". 


\section{References}

1. V. Zaalishvili, D. Melkov, B. Dzeranov, F. Morozov, G. Tuaev, International Journal of Geomate 15 (47), 158-163 (2018).

2. V. Zaalishvili, Kh. Chotchaev, Geology and Geophysics of Russian South 4, $52-67$ (2016).

3. A. Shempelev, V. Zaalishvili, S. Kukhmazov, Geotectonics 5, 20-29 (2017).

4. A. Shempelev, V. Zaalishvili, Kh. Chotchaev, S. Shamanovskaya, E. Rogozhin. Geotectonics 5, 55-69 (2020).

5. T. Giorgobiani, V. Stages, Geology and Geophysics of Russian South 10 (1), 35-42 (2020).

6. Kh. Chotchaev, V. Zaalishvili, A. Shempelev, M. Berger, O. Burdzieva, T. Zaks, V. Makiev, S. Trofimenko, Advances in Engineering Research, 68-77 (2019).

7. Kh. Chotchaev, O. Burdzieva, V. Zaalishvili, Geology and Geophysics of Russian South 10 (4), 70 - 100 (2020).

8. V. Golik, Kh. Kozhiev, O. Burdzieva, S. Maslennikov Geology and Geophysics of Russian South 9 (3), 179188 (2019).

9. V. Zaalishvili, Kh. Chotchaev, D. Melkov, O. Burdzieva, B. Dzeranov, A. Kanukov, I. Archireeva, A. Gabaraev, L. Dzobelova, E3S Web of Conferences 16401014 (2020).

10. Kh. Chotchaev, V. Zaalishvili, B. Dzeranov, Topical Problems of Green Architecture, Civil and Environmental Engineering, 07025 (2020).

11. V. Zaalishvili, D. Melkov, Innovations in Minimization of Natural and Technological Risks. Minimization of the Most Prevalent Project Risks in the Oil and Gas Industry. Abstracts 66-67 (2020.)

12. I. Bondyrev, E. Tsereteli, Ali Uzun, V. Zaalishvili, Geology and Geophysics of Russian South, v. 4-2, pp. 105-123 (2014).

13. J. Malet, O. Maquaire, E. Calais Geomorphology 43 (1-2), 33-54 (2002).

14. C. Massey, D. Petley, M. McSaveney, Engineering Geology 159, 1-19 (2013).

15. G. Herrera, F. Gutierrez, J. Garcia-Davalillo, J. Guerrero, D. Notti, J. Galve, Fernandez-Merodo, G. Cooksley, Remote Sensing of Environment 128, 31-43 (2013).

16. V. Svalova, V. Zaalishvili, G. Ganapathy, A. Nikolaev, Geology and Geophysics of Russian South 8 (2), 99 - 115 (2018).

17. V. Svalova, V. Zaalishvili, G. Ganapathy, A. Nikolaev, D. Melkov, Geology and Geophysics of Russian South 9 (2), 109-127 (2019).

18. V. Svalova, V. Zaalishvili, G. Ganapathy, A. Nikolaev, A. Ginzburg, Geology and Geophysics of Russian South 9 (2), 87-101 (2019).

19. V. Svalova, V. Zaalishvili, G. Ganapathy, P. Ivanov, Sustainable Development of Mountain Territories, v. 12(43), 162-170 (2020).

20. J. Cebulski, B. Pasierb, D. Wieczorek, A. Zielinski, Catena 195 (14), 104758 (2020).

21. J. Pelletier, B. Malamud, T. Blodgett, D. Turcotte, Engineering Geology 48 (3-4), 255-268 (1997).

22. M. Reid, S. Christian, D. Brien, Journal of Geophysical Research 105- B3, 6043-6056 (2000).

23. J. Vallance, S. Schilling, G. Devoli, M. Reid, M. Howell, D. Brien, U.S. Geological Survey Open-File Report 2001-468 18 (2004).

24. M. Reid, D. Brien, C. Waythomas, U.S. Geological Survey Professional Paper 1769, 321-332 (2010).

25. M. Reid, T. Keith, R. Kayen, N. Iverson, R. Iverson, D. Brien Bulletin of Volcanology 72, 761-766 (2010).

26. D. Brien, M. Reid, Modeling U.S. Geological Survey Scientific Investigations Report 2007-5092, 54 (2007).

27. D. Brien, M. Reid, Landslides and Engineering Geology of the Seattle, Washington, Area: Geological Society of America, Reviews in Engineering Geology XX, 83-101 (2008).

28. M. Duncan, S. Wright, Soil Strength and Slope Stability (New York, John Wiley \& Sons, 2005).

29. T. Yamagami, J. Jiang, Soils and Foundations 37 (3), 1-16 (1997).

30. D. Fredlund, J. Krahn Canadian Geotechnical Journal 14, 429-439 (1977). 
31. J. Duncan, S. Wright, The accuracy of equilibrium methods of slope stability analysis: Environmental Geology 16, 5-17 (1980).

32. O. Hungr, Geotechnique 37 (1), 113-117 (1987).

33. K. Ugai, Numerical Methods in Geomechanics, pp. 1369-1374 (1988).

34. L. Lam, D. Fredlund Canadian Geotechnical Journal 30, 905-919 (1993).

35. M. Reid, S. Christian, D. Brien, S. Henderson, Scoops3D-software to analyze three-dimensional slope stability throughout a digital landscape. Menlo Park: U.S. Geological Survey; Volcano Science Center, 2015.

36. J. Coe, W. Ellis, J. Godt, W. Savage, J. Savage, J. Michael, J. Kibler, P. Powers, D. Lidke, S. Debray, Engineering Geology 68 (1-2), 67-101 (2003).

37. W. Schulz, J. McKenna, J. Kibler, G. Biavati Landslides 6 (3), 181-190 (2009).

38. A. Handwerger, J. Roering, D. Schmidt Earth and Planetary Science Letters 377, 239-247 (2013). 